\title{
A COMPARATIVE OBSERVATIONAL STUDY OF POSTPARTUM INTRA-UTERINE CONTRACEPTIVE DEVICE INSERTIONS IN A SUB DIVISIONAL HOSPITAL AND MEDICAL COLLEGE OF BIHAR
}

\author{
Tripti Sinha ${ }^{1}$
}

${ }^{1}$ Assistant Professor, Department of Obstetrics and Gynaecology, Sri Krishna Medical College, Muzaffarpur, Bihar, India.

\section{ABSTRACT}

\section{BACKGROUND}

In order to increase the usage of birth-spacing contraceptive methods, GOI has introduced the task-sharing strategy whereby in addition to doctors, staff nurses and ANMs are also trained and entrusted with the responsibility of postpartum intrauterine contraceptive device insertion after vaginal delivery.

Aims and Objectives- This study aims to compare the outcome of this strategy at a sub-divisional hospital and medical college in Bihar and to frame recommendations to increase the success of task-sharing for PPIUCD insertions by all cadres of skilled birthattendants in health-care facilities.

Setting and Design- The study is conducted in two time-spans when the author was working in a sub-divisional hospital at Sherghaty and later at Sri Krishna Medical College, Muzaffarpur. It is a retrospective comparative observational analysis of data collected from the two levels of healthcare facilities.

\section{MATERIALS AND METHODS}

Data was collected from the PPIUCD insertion and follow-up registers maintained in both hospitals. The percentage of PPIUCD insertions after vaginal delivery and caesarean delivery, the service-provider for PPIUCD insertion, user satisfaction with the method, complications and removals were analysed.

\section{RESULTS}

Percentage of PPIUCD insertions was significantly higher at the SDH compared to the medical college. 50\% of insertions were done by nurses and ANMs in the immediate post-placental period. User satisfaction rate was high with very low complication and low removal rates. There were no PPIUCD insertions at the medical college following vaginal delivery. No systematic follow-up records were being maintained there.

\section{CONCLUSION}

In order to increase the effectiveness of the PPIUCD, the task-sharing strategy of GOI can be very effective as shown by the enthusiasm and efficiency of nurses and ANMs at the SDH. Key factors to increase the usage of this PPFP method is motivation, sensitive counseling skills and adequate training and confidence in its insertion technique.

\section{KEY WORDS}

Postpartum Family Planning (PPFP), Postpartum Intra-Uterine Contraceptive Device (PPIUCD), Task-Sharing Strategy, Nurses, and Auxiliary Nurse Midwives (ANM), Counseling, Follow-Up, Complications.

HOW TO CITE THIS ARTICLE: Sinha T. A comparative observational study of postpartum intra-uterine contraceptive device insertions in a sub divisional hospital and medical college of Bihar. J. Evolution Med. Dent. Sci. 2018;7(52):5497-5500, DOI: $10.14260 /$ jemds/2018/1216

\section{BACKGROUND}

Apart from providing incentive to increase institutional deliveries, the Janani Bal Suraksh Yojana (JBSY) as the flagship program of the Government of India (GOI) is also a laudable initiative to provide post-partum family planning method (PPFP) to women who deliver in health care facilities. Birthspacing of at least 36 months can avert $30 \%$ of maternal deaths and $10 \%$ childhood deaths.(1) However, the specter of an unmet need for contraception still looms large over vulnerable women in the reproductive age-group in India as well as other similar low-resource countries.(2,3)

'Financial or Other Competing Interest': None.

Submission 12-11-2018, Peer Review 06-12-2018,

Acceptance 12-12-2018, Published 24-12-2018.

Corresponding Author:

Dr. Tripti Sinha,

\#705 North, Udaigiri Bhawan,

Budh Marg Opposite Old Museum,

P. S. Kotwali, Patna-800001,

Bihar, India.

E-mail: triptisinha0304@gmail.com

DOI: $10.14260 /$ jemds/2018/1216
Although $40 \%$ contraceptive users still opt for sterilization, the method does not address the need for birthspacing in women who desire further pregnancies. The PPIUCD offers a safe, effective, convenient and acceptable method for such women. $(4,5)$

GOI revised its FP strategy in 2013 to permit trained GNM and ANMs to insert PPIUCD on the basis of a Bottleneck analysis.(6,7) Our study supports the task-sharing strategy for IUCD insertion by doctors and trained nurses and midwives to increase the uptake of PPIUCDs at institutional deliveries.

\section{MATERIALS AND METHODS}

This study extends over two time-frames when the author was working in the Sub-divisional hospital (SDH), Sherghaty, and Sri Krishna Medical College (SKMC), Muzaffarpur, in Bihar. The period covered in the SDH is nine months (1.1.201330.9.2013) and the period covered in the medical college is three years (1.2.2015-31.1.2018). Case notes and PPIUCD registers were the source of data for the study. In both the facilities doctors, nurses and ANMs (Trained skilled birth attendants) had received a formal 3-day standardized theoretical and hands-on training in PPIUCD insertion by 
JHpiego master trainers. This was backed up by on-site "handholding" support as and when required or asked for as well as by peer-to peer on-the job training in which a formally trained PPIUCD provider trained other staff in the task.

\section{RESULTS}

The number of deliveries during the study period at the SDH was 3049. There were 355 (11.39\%) PPIUCD insertions during this period. 176 insertions were done after vaginal delivery and 179 at Caesarean section. At the medical college there were 12000 deliveries and 962 PPIUCD insertions during this period. All were at the time of Caesarean section.

The demographic profile of PPIUCD acceptors at the SDH and medical college are almost similar. Majority of them were in the age-group $20-30$ years $(n=348,98.03 \%$ at SDH and $\mathrm{n}=906,94.17 \%$ in the medical college). 294 (82.82\%) women of parity 1-2 accepted it at SDH and 954 (99.12\%) women of parity 1-2 accepted it at the medical college. 298 (82.25\%) Hindus and 57 (16.06\%) Muslims accepted it at the SDH. At the medical college 840(87.32\%) Hindus and 122 (12.68\%) Muslims accepted it at the medical college (Table 1).

\begin{tabular}{|c|c|c|c|c|c|c|}
\hline $\begin{array}{c}\text { Name of } \\
\text { Institution }\end{array}$ & $\begin{array}{c}\text { Study Period } \\
\text { (Months) }\end{array}$ & $\begin{array}{c}\text { No. of PPIUCD } \\
\text { Insertion }\end{array}$ & $\begin{array}{c}\text { Age 20-30 Years } \\
\text { Number (\%) }\end{array}$ & $\begin{array}{c}\text { Family size=/<2 } \\
\text { Number (\%) }\end{array}$ & \multicolumn{2}{|c|}{$\begin{array}{c}\text { Religion } \\
\text { Number (\%) }\end{array}$} \\
\cline { 4 - 7 } Hindu \\
Muslim
\end{tabular}

The data from both level of health-care facility is paradoxically both encouraging and worrisome as far as the service provider doing the insertion and the timing of the insertion is concerned. At the SDH level the observation is that out of the 355 PPIUCD insertions, 176(50.14\%) were done by nurses and ANMs after vaginal delivery vis- vis 179(49.86\%) by doctors at Caesarean section. This lends support to the GOI's strategy of task-sharing in this important family planning intervention to increase contraceptive coverage and effectively reduce the unmet need of contraception of this vulnerable age-group.

At the medical college, however, it is disheartening to note that all PPIUCD insertions were in the operation theatre at the time of Caesarean section and none in the delivery room after vaginal delivery by the nursing staff despite the large case-load for vaginal deliveries. There were no insertions in the postnatal ward either in the SDH or medical college within 48 hours of delivery (Table 2).

\begin{tabular}{|c|c|c|c|}
\hline \multirow{2}{*}{ Name of Institution } & \multicolumn{2}{|c|}{ Timing of insertion } & \multirow{2}{*}{$\begin{array}{c}\text { \% of PPIUCD Acceptors of Total } \\
\text { Deliveries Conducted in Institution }\end{array}$} \\
\cline { 2 - 3 } & $\begin{array}{c}\text { Vaginal Delivery } \\
\text { Number (\%) }\end{array}$ & $\begin{array}{c}\text { Caesarean Delivery } \\
\text { Number (\%) }\end{array}$ & 11.64 \\
\hline SDH, Sherghaty & $176(50.14 \%)$ & $179(49.86 \%)$ & 2.67 \\
\hline SKMCH, Muzaffarpur & 0 & 962 & \\
\hline
\end{tabular}

\section{Table 2. Timing of PPIUCD Insertions at Sub-Divisional Hospital (SDH), Sherghaty and Sri Krishna Medical College Hospital} (SKMCH), Muzaffarpur

Another area of concern is the absence of systematic follow-up data maintained in PPIUCD follow-up registers at the medical college. At the SDH although almost half of PPIUCD acceptors defaulted for follow-up visits yet data from the PPIUCD follow-up register shows that client satisfaction rate was high with $148(83.15 \%)$ women comfortable with their contraceptive choice. Complication rate-expulsion, infection, irregular vaginal bleeding- was also low. Table-3 summarises the above findings.

\begin{tabular}{|c|c|c|c|c|}
\hline Name of Institution & Followup Clinic Visits & Satisfied Clients & Expulsions & Irregular Vaginal Bleeding/Infection \\
\hline SDH, Sherghaty & $178(50 \%)$ & $148(83.15 \%)$ & 0 & 4 \\
\hline SKMCH, Muzaffarpur & 0 & \multicolumn{3}{|c|}{ No reliable data available } \\
\hline Table 3. Followup Data at Sub-Divisional Hospital (SDH), Sherghaty and Sri Krishna Medical College Hospital (SKMCH), \\
Muzaffarpur
\end{tabular}

\begin{tabular}{|c|c|}
\hline Sl. No. & Recommendations \\
\hline 1 & $\begin{array}{c}\text { Regular orientation \& training in PPIUCD insertion to increase the number of skilled } \\
\text { birth-attendants trained in its use }\end{array}$ \\
\hline 2 & On-site follow-up support to boost confidence of service-provider \\
\hline 3 & $\begin{array}{l}\text { Increasing community awareness by enthusiastic orientation programs for ASHAs and similar cadre grass-root health- } \\
\text { workers }\end{array}$ \\
\hline 4 & IEC by television, radio, short documentaries in cinema halls, social media campaigns \\
\hline 5 & $\begin{array}{l}\text { Non-government academic forums and organisations dedicated to women's health to orient and sensitise their members } \\
\text { to provide PPIUCD in their private clinic set-up. }\end{array}$ \\
\hline 6 & $\begin{array}{c}\text { Ensuring placement of at least one/two FP counsellors in all health care facilities especially those with heavy case- loads } \\
\text { so more clients receive appropriate information about the method. }\end{array}$ \\
\hline 7 & $\begin{array}{l}\text { Ensuring that in labour ward shift at least one skilled birth-attendant is trained and confident in counseling and insertion } \\
\text { of PPIUCD }\end{array}$ \\
\hline 8 & $\begin{array}{l}\text { Ensuring post- follow-up contact with PPIUCD acceptors in hospital clinic or by telephonic enquiries to ensure method } \\
\text { continuation }\end{array}$ \\
\hline
\end{tabular}




\section{DISCUSSION}

In our study most of the acceptors of PPIUCD were in the agegroup $20-30$ years $(98.03 \%$ at the sub-divisional hospital and $94.17 \%$ at the medical college). This is similar to the findings of Lal et al.(8) Family size was $=/<2$ in our study in $82.82 \%$ women in the SDH data and $99.12 \%$ in the medical college data. This indicates that a variable proportion of women (17.17\% in the SDH and only $0.18 \%$ in the medical college data were using it as a reversible method of contraception in preference to the irreversible sterilization methods although they had 3/> more children. This preference needs to be explored since it underscores the fact that PPIUCD can be enthusiastically offered to women who have achieved the desirable optimal family size but still are hesitant for some reason/-s from accepting permanent contraception methods. Various studies like those conducted by Malichuru et al and Grimes et al have also shown that women with parity 3 or more have shown similar contraceptive choices. $(9,10)$

For any family planning intervention to be successful and popular, factors related to both client and service-provider are important. The observation that although nursing staff at both the SDH and medical college were trained in post-placental IUCD insertion, there were no PPIUCD insertions following vaginal delivery by the nursing staff in the medical college is worrying. This can be accounted for two reasons. The extremely busy under-staffed labour ward in the medical college did not allow time for doctors and nurses to counsel parturient women regarding the advantages and availability of the CuT device in the hospital. The absence of a family planning counsellor who could counsel antenatal patients in the antenatal clinic, labour suite in early labour or in the postnatal ward within 48 hours of delivery is another very important reason why acceptance rate was so low in the medical college. In the SDH there was a dedicated, trained female FP counsellor who supported the antenatal clinic and did rounds in the postnatal ward also. This gave ample opportunity for women to be offered the basket of contraceptive choices available to them. The presence of a FP counsellor would have had a positive impact on the acceptance of PPIUCD in the medical college. A study in India by Yadav et al compared the follow-up data at 6 weeks on PPIUCD insertion in women who had the device inserted by either doctors or nurses. They concluded that trained nurses and midwives who conduct deliveries at public health facilities can perform PPIUCD insertion as safely as doctors.(11) A multi-centre study conducted in six lowresource countries by JHpiego also reported satisfaction outcomes when IUCD was inserted post-delivery by doctors, midwives or doctors.(12) On the basis of this robust study they strongly advocated the PPIUCD insertion roll-out and implementation policy though accepting the operational challenges to its success.

Another area of concern is at the medical college is the observation that there was no structured follow-up of patients who had IUCDs inserted at Caesarean section. Hence, the usersatisfaction rates could not be ascertained on reliable data. At the SDH the high user- satisfaction rate and low incidence of complications like expulsion, infection and irregular vaginal bleeding lends support to the strategy the all levels of skilled birth attendants could and should be trained in this effective PPFP intervention.

Considering the abundant delivery rate at the teaching hospital, it is not difficult to appreciate why there was a very low rate of PPIUCD insertions following vaginal deliveries. Family planning counsellors will have a positive impact on its acceptance by interacting with eligible women and their families during antenatal visits, early labour and in postnatal wards before discharge.

Another worrying observation at the teaching hospital was the absence of a regular follow-up protocol after PPIUCD insertions. No reliable data regarding user satisfaction or complication/removals could be collected. There were a significant number of removals under G.A. although it was not clear from the records when the PPIIUCD was inserted and why the user wanted its removal. At the sub-divisional hospital, on the other hand, such register was maintained, and data showed a high rate of user satisfaction and low complication rate.

Our observations underline several important messages for the PPIUCD program policy and implementation. The motivation and training of the skilled birth attendants is of paramount importance for acceptance of PPIUCD. Given the time constraints in the antenatal clinic and delivery suites counseling can only be done effectively by well-oriented and trained FP counsellors who could cater also to the needs of the acceptors later in the follow- up period as and when required.

\section{CONCLUSION}

Data relating to the medical college gives cause for concern since there were no CuT insertions in the labour suite after vaginal delivery. Also, over the three-year observation period there was fall in the PPIUCD insertion also at caesarean delivery.

The sub-divisional hospital data, though encouraging as far as task-sharing strategy for PPIUCD insertions is concerned, should not give way to complacency. Current data should be re-visited to ensure that the acceptance and continuation rates remain satisfactory.

Table 4 summarizes recommendations for the on-site action plan to improve and/or maintain PPIUCD uptake rates at both levels of health care. This can serve as template for other facilities in the state. This requires commitment from all stake-holders concerned policy-makers, service-providers, non-governmental organizations committed to spreading contraceptive awareness and acceptance in the community as well as local community leaders across all sections of the society.

It would be an interesting area of research to enquire into the perception of PPIUCD service-providers in health-care facilities and of community health workers like ASHAs about this PPFP option and the difficulties they experience in getting women to accept and continue with this method. Lack of motivation or confidence in these stake-holders in the PPFP program would nullify the GOI's efforts to increase usage of this birth-spacing contraception which has proved its impact where this program has been successful.

\section{REFERENCES}

[1] WHO. Programming Strategies for PPFP. Geneva: WHO, 2013.

[2] Borda M. Family planning needs during the extended postpartum period in India. Access FP Initiative Brief: 
2009. (http.//www.access to health.org/toolres/pdfs/ India_Analysis.pdf (accessed 12 March 2015)

[3] Ross JA, Winfrey WL. Contraceptive use, intention to use and unmet need during the extended postpartum period. Int Fam Plan Perspect 2001;27(1):20-7.

[4] Kumar S, Sethi R, Balasubramaniam S, et al. Women's experience with postpartum intrauterine device use in India. Reprod Health 2014;11(1):32.

[5] Patnaik UK, Mishra TK. User satisfaction and retention of Cu-T IUD among rural women in Orissa. Health Popul Perspect Issues 2003;26:52-8.

[6] Government of India. A strategic approach to reproductive, maternal, newborn, child and adolescent health: (RMNCH-a) in India. New Delhi: Ministry of Health \& Family Welfare, 2013.

[7] World Health Organisation (WHO). Reproductive Health and Research. WHO recommendations: optimizing health worker roles to improve access to key maternal and newborn health interventions through task shifting: 2012. http://www.ncbi.nlm.nih.gov/books/NBK148518/(ac cessed 22 May 2015]
[8] Lall J, Nagar 0. Comparative study of post-placental cut insertion following vaginal and Caesarean delivery. Int J Reprod Contracept Obstet Gynecol 2017;6(3):901-6.

[9] Maluchuru S, Aruna V, Prabhavathi N. Postpartum intrauterine device insertion: 2 year experience at a tertiary care centre in Guntur Medical College/ Govt. General Hospital, Guntur. IOSR J Dent Med Sci 2015;14(3):56-61.

[10] Grimes D, Schulz K, van Vliet H, et al. Immediate postpartum insertion of intrauterine devices: a Cochrane review. Hum Reprod 2002;17(3):549-54.

[11] Yadav V, Balasubramaniam S, Das S, et al. Comparison of outcomes at 6 weeks following postpartum intrauterine contraceptive device insertions by doctors and nurses in India: a case-control study. Contraception 2016;93(4)347-55.

[12] Pfitzer A, Mackenzie D, Blanchard H, et al. A facility birth can be the time to start family planning: Postpartum intrauterine device experiences from six countries. Int J Gynecol Obstet 2015;130(Suppl 2):S54S61. 